\title{
Label-free electrochemical differentiation of phosphorylated and non-phosphorylated peptide by electro-catalyzed tyrosine oxidation $\uparrow$
}

\author{
Na Qu, Bin Wan and Liang-Hong Guo* \\ Received 28th April 2008, Accepted 3rd July 2008 \\ First published as an Advance Article on the web 28th July 2008 \\ DOI: 10.1039/b807133k
}

Protein phosphorylation plays an important role in many significant cellular processes, and has thus gained tremendous interest in the field of proteomics. The electro-active tyrosine residue, as an important receptor of phosphorylation in proteins, exhibits electro-inactivity after being phosphorylated on the hydroxy group of its aromatic ring. In this study, the electrochemical oxidation of tyrosine on indium tin oxide (ITO) electrodes was catalyzed with an electron mediator Os(bpy) ${ }_{3}{ }^{2+}$ (bpy $=2,2^{\prime}$-bipyridine) and was employed as a signal reporter to differentially detect non-phosphorylated and phosphorylated peptides. A short, tyrosine-containing peptide glu-glu-glu-glu-glu-tyr (EY-6) was immobilized on an ITO surface using the layer-by-layer self-assembly method, and was detected by cyclic voltammetry in an Os(bpy $)_{3}{ }^{2+}$ solution. The limit of detection was about $0.23 \mu \mathrm{g} \mathrm{mL}{ }^{-1}$ EY-6 in solution. The phosphorylated peptide glu-glu-glu-glu-glu-tyr-OP (EY-6P) did not produce an appreciable oxidation current on the electrode. Surface plasmon resonance measurements revealed that the amount of EY-6 and EY-6P adsorbed on the sensor chip surface was 269 and $378 \mathrm{pg} \mathrm{mm}^{-2}$, respectively. The poly(glu, tyr) $(4: 1)$ peptide, a protein tyrosine kinase substrate, was also detected by the same approach, with a detection limit of $0.65 \mu \mathrm{g} \mathrm{mL} \mathrm{L}^{-1}$. This new approach offers the possibility of label-free and on-chip detection of protein tyrosine kinase activity.

\section{Introduction}

Protein phosphorylation and dephosphorylation are involved in numerous cellular activities in living organisms. ${ }^{1}$ Because of the fundamental roles in regulating gene expression and protein synthesis, which further control important biological processes such as cellular signal transduction, cell division and cancer, protein phosphorylation has gained tremendous interest in the field of proteomics. Protein phosphorylation mainly occurs on serine, threonine and tyrosine residues in vivo. The phosphorylation of tyrosine, for example, is catalyzed by protein tyrosine kinases (PKAs), which transfer a phosphoryl group from ATP to the hydroxy group on the tyrosine aromatic ring.

Current detection methods for the identification of protein phosphorylation include radiolabeling, ${ }^{2}$ immunoassay, ${ }^{3}$ fluorescence labeling ${ }^{4}$ and HPLC. ${ }^{5}$ A few more general phosphorprotein detection methods including the Pro-Q Diamond $\operatorname{stain}^{6}$ have been commercialized. Owing to its high sensitivity and specificity, mass spectrometry has become a popular technique for studying protein phosphorylation. ${ }^{7-9}$ Mrksich's group $^{10}$ employed MALDI-TOF mass spectrometry to evaluate kinase activities rapidly and semi-quantitatively on peptide chips

State Key Laboratory of Environmental Chemistry and Ecotoxicology, Research Center for Eco-environmental Sciences, Chinese Academy of Sciences, P.O. Box 2871, 18 Shuangqing Road, Beijing 100085, China. E-mail: LHGuo@rcees.ac.cn; Fax: +86-10-62849685;

Tel: $+86-10-62849685$

$\dagger$ This paper is part of an Analyst themed issue highlighting Chinese science, with guest editor Mengsu (Michael) Yang. prepared by self-assembled monolayers on gold. The method is label-free and suitable for high-throughput screening. However, the above-mentioned techniques are either labor- and timeintensive, or require highly specialized laboratory instruments and well-trained personnel.

It has been found that the amino acid tyrosine can be electrochemically oxidized with irreversible characteristics at carbon and metal electrodes. ${ }^{11}$ Electrochemical detection of tyrosinecontaining peptides and proteins has also been performed at carbon electrodes. ${ }^{12,13}$ Palecek's group reported the sensitive electrochemical detection of native and aggregated $\alpha$-synuclein (a protein involved in Parkinson's disease) by monitoring tyrosine oxidation on carbon electrodes. ${ }^{14}$ Vestergaard et al. ${ }^{15}$ reported the electrochemical detection of the aggregation process of amyloid peptides related to Alzheimer's disease based on the tyrosine oxidation signal on carbon. Label-free electrochemical detection of urea-induced protein unfolding was carried out in our group by monitoring the electro-catalytic oxidation current of tyrosine residues in bovine serum albumin on indium tin oxide (ITO) electrodes with a metal complex. ${ }^{16}$ Recently, the electrochemical oxidation currents of tyrosine and phosphortyrosine at a screen-printed carbon electrode (SPCE) were compared. ${ }^{17}$ Furthermore, inhibition of the enzymatic tyrosine phosphorylation reaction on magnetic beads was monitored by following the rise of the tyrosine oxidation current on a SPCE electrode. ${ }^{18}$ All of the above studies indicate that tyrosine is not only an important phosphorylation target in proteins, but also a well-defined electrochemical signal reporter, suggesting the potential use of tyrosine electrochemistry for exploring some biological processes. 
In this study, we intend to explore the feasibility of using tyrosine electrochemistry to detect protein phosphorylation. Our results reveal that the oxidation current of tyrosine in peptides is electrochemically catalyzed on ITO electrodes by an electron mediator Os(bpy) ${ }_{3}{ }^{2+}$ (bpy $=2,2^{\prime}$-bipyridine), whereas the phosphorylated peptide is barely detectable. The electrochemical differentiation on ITO between phosphorylated and non-phosphorylated tyrosine has provided the basis for the label-free and on-chip detection of protein phosphorylation.

\section{Experimental}

\section{Materials}

L-tyrosine was obtained from Shanghai Biochemicals (Shanghai, China). Poly(diallyldimethyl ammonium chloride) (PDDA), 3-mercaptopropionic acid (MPA), o-phospho-L-tyrosine and poly(glu, tyr) (4:1) sodium salt were obtained from Sigma Aldrich (St. Louis, MO, USA) and used as received. The two short peptides, glu-glu-glu-glu-glu-tyr (EY-6) and glu-glu-gluglu-glu-tyr $\left(\mathrm{PO}_{3} \mathrm{H}_{2}\right)$ (EY-6P) (purity 98\%), were synthesized by Invitrogen (Carlsbad, California, USA). Positively-charged peptide lys-lys-lys-lys-lys-tyr (KY-6) (purity 98\%) was synthesized by GL Biochemicals (Shanghai, China). The metal complex Os(bpy) ${ }_{3} \mathrm{Cl}_{2}$ was prepared according to the procedures described elsewhere. ${ }^{19}$

\section{Fabrication of peptide biosensor}

ITO electrodes (working area $25 \mathrm{~mm}^{2}$ ) were fabricated and cleaned according to the established procedure. ${ }^{16}$ Peptides were immobilized on the ITO surface by a layer-by-layer electrostatic adsorption technique, as depicted in Scheme 1. First, an electrode was immersed in positively-charged PDDA solution ( $2 \mathrm{mg} \mathrm{mL}^{-1}$ in $20 \mathrm{mM}$ phosphate, $\mathrm{pH} \mathrm{7.3)} \mathrm{for} \mathrm{one} \mathrm{hour.} \mathrm{After}$ rinsing with water, the electrode was then immersed for $30 \mathrm{~min}$ in a peptide solution in $20 \mathrm{mM}$ phosphate, $\mathrm{pH}$ 7.3. Cyclic voltammetry was performed on a CHI 660B electrochemistry analyzer (Austin, TX, USA) with a Pt counter electrode and a $3 \mathrm{M} \mathrm{Ag} / \mathrm{AgCl}$ reference electrode.

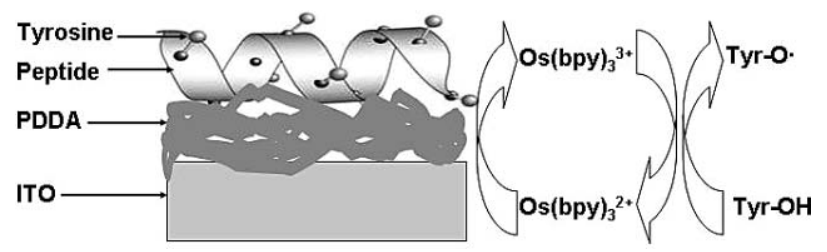

Scheme 1 Schematic diagram of layer-by-layer assembled peptide sensor surface.

\section{Surface plasmon resonance}

Surface plasmon resonance (SPR) measurements were performed on a BI-SPR1000 system from Biosensing Instrument (Tempe, AZ, USA). To mimic peptide adsorption on the ITO surface, the gold sensor chip was modified with MPA to obtain a negatively-charged surface, on which a PDDA layer was immobilized by electrostatic adsorption. A peptide solution
(26 $\mu \mathrm{g} \mathrm{mL}^{-1}$ EY-6, $28 \mu \mathrm{g} \mathrm{mL}^{-1}$ EY-6P or $25 \mu \mathrm{g} \mathrm{mL}^{-1} \mathrm{KY}-6$ ) was then injected into the sensor channel at a flow rate of $5 \mu \mathrm{L} \mathrm{min}{ }^{-1}$ for SPR measurement. To avoid destruction of the electrostatic interaction between the peptide and PDDA during the flow, water was used to dissolve the peptides and also as the carrier solution.

\section{Results and discussion}

In our previous study, ${ }^{16}$ it was demonstrated that the tyrosine amino acid and the residues in bovine serum albumin could be electro-catalytically oxidized on ITO electrodes with an osmium polypyridyl complex. The oxidation current of tyrosine is low on the ITO electrode without Os(bpy $)_{3}{ }^{2+}$, but is greatly enhanced in the presence of $\mathrm{Os}(\mathrm{bpy})_{3}{ }^{2+}$. The addition of $\mathrm{Os}(\mathrm{bpy})_{3}{ }^{2+}$ to the tyrosine solution produced catalytic voltammograms that could be rationalized by assuming the mechanism in eqn (1) and eqn (2):

$$
\begin{gathered}
\mathrm{Os}(\mathrm{bpy})_{3}{ }^{2+} \rightarrow \mathrm{Os}(\mathrm{bpy})_{3}{ }^{3+}+\mathrm{e} \\
\mathrm{Os}(\mathrm{bpy})_{3}{ }^{3+}+\mathrm{TyrO}^{-} \rightarrow \mathrm{Os}(\mathrm{bpy})_{3}{ }^{2+}+\mathrm{TyrO}^{\circ}
\end{gathered}
$$

Tyrosine oxidation proceeds by the conversion of the aromatic phenol group into a phenoxonium group and then undergoes reactions to produce several products including quinol. ${ }^{20}$ It can be postulated that, by losing the phenol group after tyrosine phosphorylation, the phosphorylated residue would not be oxidized by the same route. Very recently, Kerman's group ${ }^{17}$ has demonstrated very clearly the different electrochemical reactivity between phosphorylated and non-phosphorylated tyrosine on carbon electrodes. The difference was also observed on ITO electrodes with Os(bpy $)_{3}{ }^{2+}$ as the mediator, as illustrated in Fig. 1. For $100 \mu \mathrm{M}$ phosphorylated tyrosine amino acid dissolved in solution, its oxidation current was only slightly above the background (due to mediator electro-oxidation). However, for the non-phosphorylated amino acid, the current was about 18-fold higher.

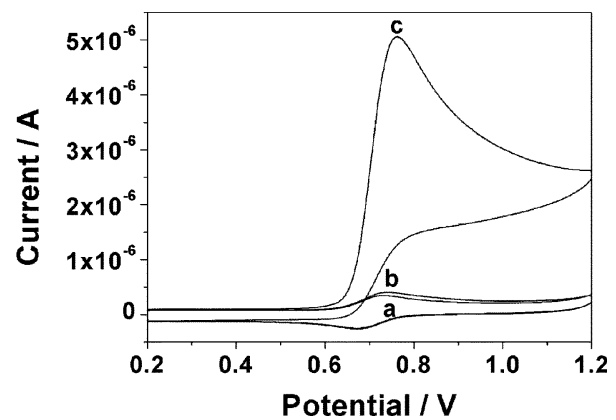

Fig. 1 Cyclic voltammograms of bare ITO electrodes in (a) $3 \mu \mathrm{M}$ Os(bpy) ${ }_{3}{ }^{2+}$ solution, (b) $3 \mu \mathrm{M}$ Os(bpy $)_{3}{ }^{2+}$ and $100 \mu \mathrm{M}$ phosphorylated tyrosine solution, and (c) $3 \mu \mathrm{M}$ Os(bpy) ${ }_{3}{ }^{2+}$ and $100 \mu \mathrm{M}$ tyrosine solution. Supporting electrolyte: $20 \mathrm{mM}$ phosphate, $\mathrm{pH}$ 7.3. Scan rate $30 \mathrm{mV} \mathrm{s}^{-1}$.

Similar results were obtained with tyrosine-containing synthetic peptides adsorbed on ITO electrodes [Fig. 2(A)]. The peptide was adsorbed on a PDDA-modified ITO surface by the electrostatic attraction between the positively-charged polymer and the negatively-charged glutamine residues of the 
(A)

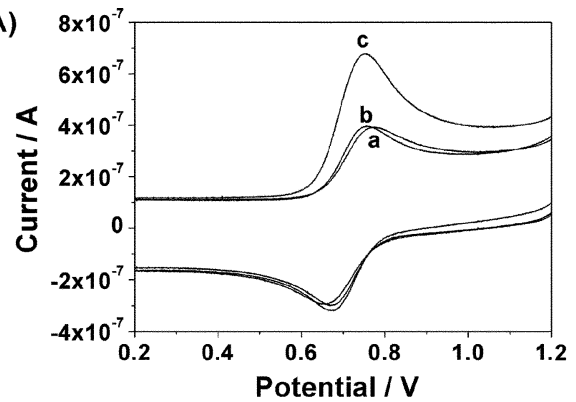

(B)

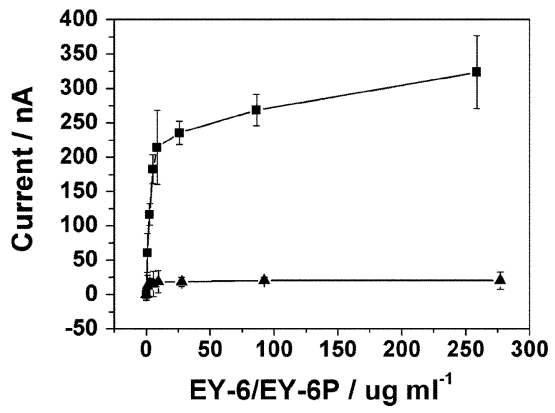

Fig. 2 (A) Cyclic voltammograms of $3 \mu \mathrm{M} \mathrm{Os(bpy)})_{3}{ }^{2+}$ with (a) PDDAmodified ITO, (b) PDDA-modified ITO adsorbed in $100 \mu \mathrm{M}(92 \mu \mathrm{g}$ $\left.\mathrm{mL}^{-1}\right)$ EY-6P, and (c) PDDA-modified ITO adsorbed in $100 \mu \mathrm{M}(86 \mu \mathrm{g}$ $\mathrm{mL}^{-1}$ ) EY-6. Supporting electrolyte: $20 \mathrm{mM}$ phosphate, $\mathrm{pH}$ 7.3. Scan rate $30 \mathrm{mV} \mathrm{s}^{-1}$. (B) Plot of background-subtracted oxidation current as a function of EY-6 ( $\mathbf{\square})$ and EY-6P $(\boldsymbol{\Delta})$ concentration for PDDA-modified ITO adsorption. Each data point is the average of three electrodes.

peptide. For the non-phosphorylated peptide, the backgroundsubtracted current increased rapidly with the peptide concentration from 0 to $5 \mu \mathrm{g} \mathrm{mL}^{-1}$, reflecting strong surface adsorption. At concentrations above $5 \mu \mathrm{g} \mathrm{mL}^{-1}$, the current increased only modestly, suggesting surface saturation [Fig. 2(B)]. The limit of detection for the EY- 6 peptide is about $0.23 \mu \mathrm{g} \mathrm{mL}^{-1}$ (three times the standard deviation above background). By contrast, the phosphorylated peptide did not show an appreciable response. The response of Os(bpy $)_{3}{ }^{2+}$ on the PDDA-modified ITO electrode is very close to the bare electrode. The similarity has been observed in other systems, ${ }^{21}$ and may be rationalized by the porous and disordered structure of the polymer films..$^{22}$ This actually provides a great advantage for electro-catalyzed tyrosine oxidation over direct electrochemical oxidation, as discussed in the Conclusions section.

The amount of surface-adsorbed peptide was quantified by SPR measurement, using an MPA-modified gold chip to mimic an ITO surface. After exposing the sensor chip to $30 \mu \mathrm{M}$ $\left(26 \mu \mathrm{g} \mathrm{mL}^{-1}\right)$ EY-6 or $30 \mu \mathrm{M}\left(28 \mu \mathrm{g} \mathrm{m}^{-1}\right)$ EY-6P peptide, the amount of peptide adsorbed on the surface was estimated to be $269 \pm 9$ and $378 \pm 18 \mathrm{pg} \mathrm{mm}^{-2}$ respectively, based on the increase in SPR response after it reached steady-state (Fig. 3). The negative phosphate group in EY-6P probably helped in bringing more phosphorylated peptide onto the surface. Since the phosphorylated peptide adsorbed more on the surface than the non-phosphorylated one, the lack of electrochemical response can be attributed to its low electrochemical reactivity. Moreover, to examine the possibility of non-specific adsorption, the positively-charged peptide lys-lys-lys-lys-lys-tyr (KY-6) was also evaluated. As shown in Fig. 3, the adsorption of KY-6 on

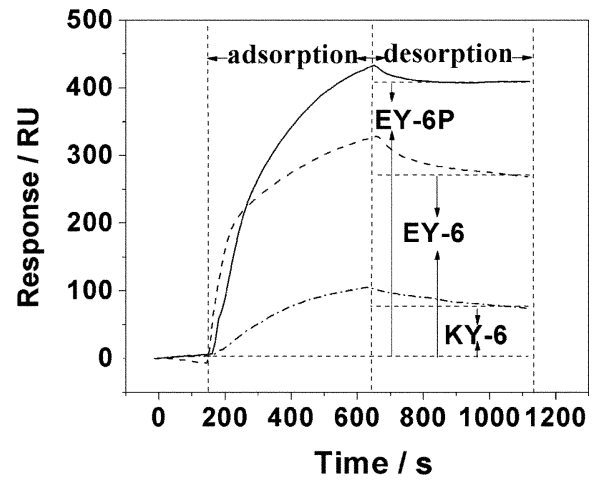

Fig. 3 SPR response change on PDDA-modified gold sensor chip for the binding of $30 \mu \mathrm{M}\left(26 \mu \mathrm{g} \mathrm{mL}^{-1}\right)$ EY-6 (---), $30 \mu \mathrm{M}\left(28 \mu \mathrm{g} \mathrm{mL}^{-1}\right)$ EY-6P (一) and $30 \mu \mathrm{M}\left(25 \mu \mathrm{g} \mathrm{mL}^{-1}\right) \mathrm{KY}-6(-\cdot-)$. Carrier solution: pure

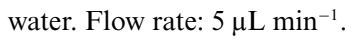

the sensor surface was estimated to be $77 \pm 6 \mathrm{pg} \mathrm{mm}^{-2}$, which is substantially less than the two negatively-charged peptides. The non-specific adsorption may be caused by the hydrophobic interaction between the tyrosine residues and the surface.

The poly(glu, tyr) $(4: 1)$ peptide is a common substrate of protein tyrosine kinases. It was also adsorbed on PDDAmodified ITO electrodes and detected electro-catalytically. As depicted in Fig. 4, a current-concentration curve similar to that of EY-6 was obtained. From the plot, the limit of detection for poly(glu, tyr) $(4: 1)$ is estimated as $0.65 \mu \mathrm{g} \mathrm{mL}^{-1}$ (three times the standard deviation above background). Since the polypeptide is heterogeneous in its length, a mass concentration in $\mu \mathrm{g} \mathrm{mL}^{-1}$ is used instead of molar concentration. The peak-shaped catalytic voltammogram is due to depletion of the limited amount of peptides immobilized on the electrode.

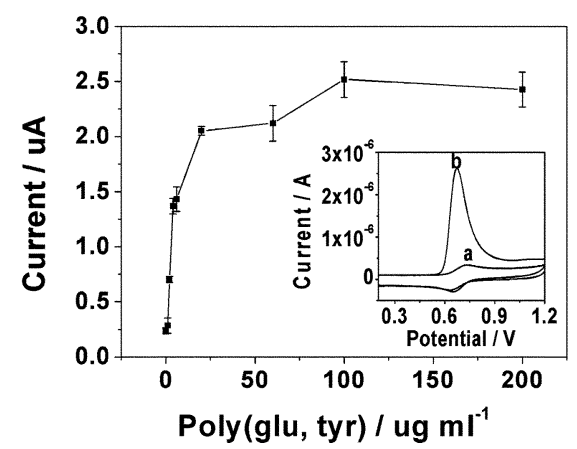

Fig. 4 Plot of the background-subtracted oxidation current as a function of poly(glu, tyr) concentration for PDDA-modified ITO adsorption. Each data point is the average of three electrodes. Inset: cyclic voltammograms of $3 \mu \mathrm{M}$ Os(bpy $)_{3}{ }^{2+}$ with (a) PDDA-modified ITO, (b) PDDA-modified ITO adsorbed in $100 \mu \mathrm{g} \mathrm{mL}^{-1}$ poly(glu, tyr). Supporting electrolyte: $20 \mathrm{mM}$ phosphate, $\mathrm{pH}$ 7.3. Scan rate $30 \mathrm{mV} \mathrm{s}^{-1}$.

Although only negatively-charged peptides were investigated in this study, our approach is broadly applicable. Both negatively- and positively-charged peptides can be immobilized on the ITO surface by the layer-by-layer assembly method, as already shown by many researchers in their work. ${ }^{23}$ Alternatively, silane chemistry can be employed to immobilize peptides to the surface covalently, which is not limited to charged peptides. 


\section{Conclusions}

To conclude, the feasibility of using electrochemically-catalyzed tyrosine oxidation to detect protein phosphorylation was demonstrated in this work. A substantial difference in the electrochemical response between phosphorylated and nonphosphorylated tyrosine amino acid and tyrosine-containing peptides was observed. The results have provided the basis for the label-free detection of protein phosphorylation. Previous studies by Kerman and others ${ }^{14,15,17,18}$ all employed the direct oxidation of tyrosine on carbon electrodes as a signal to monitor the biochemical processes. A potential problem of the approach is the slow electrochemical kinetics when biomolecules under study are immobilized on electrodes through poorly conducting organic modification layers. By comparison, our strategy should be less prone to the problem, since the mediator diffuses freely in solution and seems to be insensitive to the underlying polymer layer. There are readily available surface modification methods for ITO electrodes, such as layer-by-layer assembly and silane chemistry. Therefore, the current system is well suited for labelfree and, in particular, the on-chip detection of protein tyrosine kinase activity.

\section{Acknowledgements}

This work was supported by the National Natural Science Foundation of China (20675087, 20621703) and the Chinese Academy of Sciences.

\section{References}

1 T. Pawson and J. D. Scott, Science, 1997, 278, 2075-2080

2 M. Sandberg, E Butt, C. Nolte, L. Fischer, M. Halbrugge, J. Beltman, T. Jahnsen, H. G. Genieser, B. Jastorff and U. Walter, Biochem. J., 1991, 279, 521-527.
3 Goldstein, K. Y. Lee, J. Y. Lew, K. Harada, J. Wu, J. W. Haycock, T. Hokfelt and A. Y. Deutch, J. Neurochem., 1995, 64, 22812287.

4 K. Martin, T. H. Steinberg, L. A. Cooley, K. R. Gee, J. M. Beechem and W. F. Patton, Proteomics, 2003, 3, 1244-1255.

5 X. Yan, N. H. Packer, A. A. Gooley and K. L. Williams, J. Chromatogr., A, 1998, 808, 23-41.

6 H. Steinberg, B. J. Agnew, K. R. Gee, W.-Y. Leung, T. Goodman, B. Schulenberg, J. Hendrickson, J. M. Beechem, R. P. Haugland and W. F. Patton, Proteomics, 2003, 3, 1128-1144.

7 Y.-P. Kim, E. Oh, Y.-H. Oh, D. W. Moon, T. G. Lee and H.-S. Kim, Angew. Chem., Int. Ed., 2007, 46, 6816-6819.

8 R. Aebersold and M. Mann, Nature, 2003, 422, 198-207.

9 A. P. Navaza, J. R. Encinar and A. Sanz-Medel, Angew. Chem., Int. Ed., 2007, 46, 569-571.

10 W.-S. Yeo, D.-H. Min, R. W. Hsieh, G. L. Greene and M. Mrksich, Angew. Chem., Int. Ed., 2005, 44, 5480-5483.

11 V. Brabec and V. Mornstein, Biophys. Chem., 1980, 12, 159-165.

12 X. Cai, G. Rivas, P. A. M. Farias, H. Shiraishi, J. Wang and E. Palecek, Anal. Chim. Acta, 1996, 332, 49-57.

13 J. A. Reynaud, B. Malfoy and A. Bere, J. Electroanal. Chem., 1980, 116, 595-606.

14 M. Masarik, A. Stobiecka, R. Kizek, F. Jelen, Z. Pechan, W. Hoyer, T. M. Jovin, V. Subramaniam and E. Palecek, Electroanalysis, 2004, 16, 1172-1181.

15 M. Vestergaard, K. Kerman, M. Saito, N. Nagatani, Y. Takamura and E. Tamiya, J. Am. Chem. Soc., 2005, 127, 11892-11893.

16 L.-H. Guo and N. Qu, Anal. Chem., 2006, 78, 6275-6278.

17 K. Kerman, M. Vestergaard, M. Chikae, S. Yamamura and E. Tamiya, Electrochem. Commun., 2007, 9, 976-980.

18 K. Kerman, M. Vestergaard and E. Tamiya, Anal. Chem., 2007, 79, $6881-6885$.

19 T. W Hamann, F. Gstrein, B. S. Brunschwig and N. S. Lewis, J. Am. Chem. Soc., 2005, 127, 7815-7824.

20 H. P. Pelmentier, U. Jurva, B. Barroso and A. P. Bruins, Rapid Commun. Mass Spectrom., 2003, 17, 1585-1592.

21 J. F. Rusling, Biosens. Bioelectron., 2004, 20, 1022-1028.

22 J. F. Rusling and R. J. Forster, J. Colloid Interface Sci., 2003, 262, $1-15$.

23 M. Tominaga, K. Soejima, M. Matsumoto and I. Taniguchi, J. Electroanal. Chem., 2005, 579, 51-58. 